\title{
Patterns of small fish distributions in seagrass beds in a temperate Australian estuary
}

\author{
Jane E. Jelbart**, Pauline M. Ross* and Rod M. Connolly ${ }^{\dagger}$ \\ *University of Western Sydney, College of Science, Technology and Environment, Locked Bag No. 1797, Penrith DG, New South \\ Wales, Australia 1797. ${ }^{\dagger}$ Griffith University, Australian Rivers Institute-Coasts and Estuaries, PMB 50, Gold Coast Mail Centre, \\ Queensland, Australia 9726. ${ }^{\ddagger}$ Corresponding author, e-mail: jane.jelbart@newcastle.edu.au
}

Beds of the seagrass Zostera capricorni are an integral part of the estuarine landscape along the east coast of Australia, forming an important habitat for juvenile fish. Seagrass beds can vary in their size, shape and patchiness of seagrass cover as well as their distance from the estuary mouth. We tested for a correlation between these features and small fish assemblages in seagrass. Fifteen beds were selected from three sizecategories (small, 980 to $2300 \mathrm{~m}^{2}$; medium, 3375 to $4090 \mathrm{~m}^{2}$; and large, 5335 to $6630 \mathrm{~m}^{2}$ ). We found that the size of beds, the patchiness of seagrass cover and location within the estuary (distance from estuary mouth) were all related to differences in fish assemblages. There were greater densities of fish species in small $(10.3$ \pm 0.79 species. net $\left.^{-1}\right)$ compared to medium $(7.6 \pm 0.6)$ and large $(8.2 \pm 0.5)$ beds. This occurred regardless of bed placement within the estuary, its patchiness or time of sampling (day and night). The fish assemblages within seagrass beds also changed as bed distance to estuary mouth increased. Six species had greater densities in beds closer to the estuary mouth, while only two species were in greater densities far from the mouth. Fish assemblages were different between beds with patchy and continuous cover, although total densities of all fish species combined were similar. There were greater densities of four species in continuous beds compared to two species that were greater in patchy beds. Overall, an important finding was that even small patchy seagrass beds contain greater densities of small fish species than larger beds with continuous seagrass cover.

\section{INTRODUCTION}

Beds of the seagrass Zostera capricorni are a conspicuous component of estuarine landscapes along the temperate south-eastern coast of Australia. They are important habitats for juvenile fish and small, inconspicuous adult fish (Bell \& Pollard, 1989) and, like shallow seagrasses elsewhere (Jackson et al., 2001, 2002), typically support a higher abundance and diversity of fish than adjacent unvegetated habitats (Ferrell \& Bell, 1991). Seagrass occurs naturally as small and large beds of different shapes, but human activities have in places reduced existing beds to smaller remnant patches surrounded by unvegetated sand (Short \& Wyllie-Echeverria, 1996).

The influence of seagrass landscape features on associated fauna, including fish, has been considered in two recent reviews (Boström et al., 2006; Connolly \& Hindell, 2006). Both reviews stress the importance of defining the (temporal and spatial) scales at which studies on fauna are conducted. The spatial scales investigated in this study ranged from the density of seagrass shoots (centimetres), to the patchiness of seagrass cover (metres), to the size and shape of seagrass beds (tens to hundreds of metres), to location of the bed within the estuary (kilometres).

There is strong evidence that a combination of spatial scales could be influencing fish densities and assemblages in seagrass beds. These include a combination of scales from shoot density (e.g. Heck \& Orth, 1980; Bell \& Westoby,
1986; Jackson et al., 2006a), to patchiness of seagrass cover (e.g. Salita et al., 2003; Jackson et al., 2006a), the size of beds (e.g. McNeill \& Fairweather, 1993; Laurel et al., 2003), and across whole estuaries (e.g. Jenkins et al., 1996; Moranta et al., 2006). For this reason we have combined these features so that we could test for interactions between these landscape spatial scales. The small fish investigated in this study are classed as megafauna (>10 mm) and so could be expected to respond to the spatial scales of shoot density, patchiness of cover and size of bed (Attrill et al., 2000).

The influences of seagrass shoot density and leaf length on fish assemblages have been investigated by numerous researchers (e.g. Heck \& Orth, 1980; Bell \& Westoby, 1986; Jackson et al., 2006a) and their effects are usually at the single species level or for a class of fish (e.g. cryptic species). However, any study of seagrass fish needs to take into account any possible confounding influence of these smallscale features.

Another feature of seagrass that may influence fish assemblages is patchiness of seagrass cover, which can be a continuum from very sparse, patchy cover to dense, continuous cover. The number of small bare patches within a bed is a separate aspect of seagrass landscapes to the length of the outer perimeter of beds. The cover of a seagrass bed has been demonstrated to influence the density or survivorship of seagrass infauna (Irlandi, 1994; Bell et al., 2002; Healey \& Hovel, 2004; Hovel \& Fonseca, 2005). The 


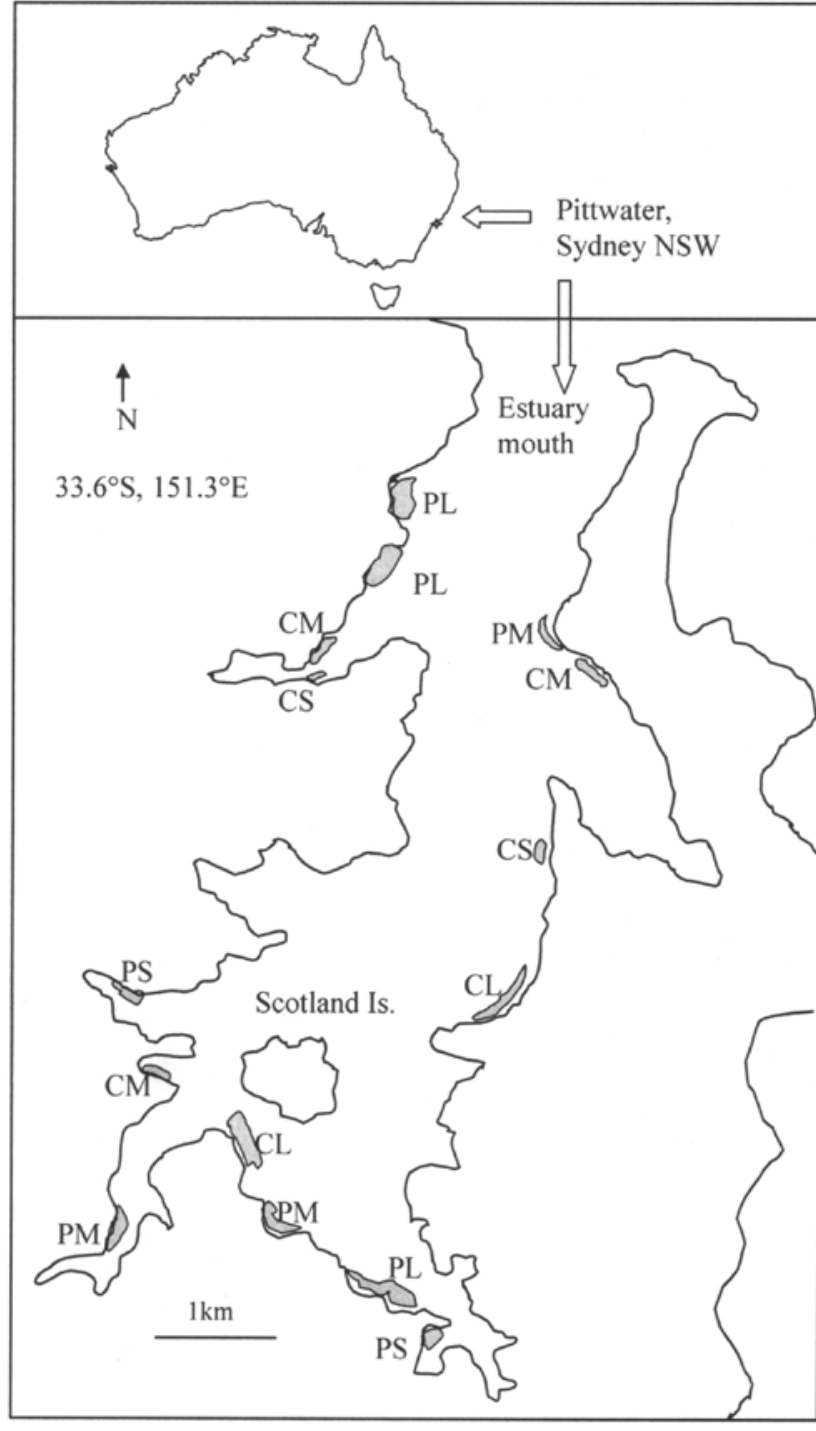

Figure 1. A map of Australia showing the location of the Pittwater estuary and details of the estuary. The seagrass beds are labelled according to their relative size $(\mathrm{L}$, large; $\mathrm{M}$, medium; $\mathrm{S}$, small) and cover ( $\mathrm{C}$, continuous beds; $\mathrm{P}$, patchy beds).

survivorship of the blue crab Callinectes sapidus was higher in patchy than continuous natural seagrass (Hovel \& Fonseca, 2005), and densities of the gastropod Acteocina inculta were higher in patchy than continuous artificial seagrass (Healey \& Hovel, 2004). Similarly, abundance of the pipefish Syngnathus scovelli was higher in scarred seagrass compared to continuous seagrass (Bell et al., 2002). In contrast, survivorship of the hard clam Mercenaria mercenaria was lower in patchy than continuous natural seagrass (Irlandi, 1994). Given the different responses of species, we expected the effects of seagrass patchiness on fish in our study to vary for different species.

There has been much research on the effect of seagrass patch or bed size on macroinvertebrates (e.g. Eggleston et al., 1998; 1999; Irlandi et al., 1999; Bologna \& Heck, 2000; Bell et al., 2001; Hovel \& Lipcius, 2001; Hovel \& Fonseca, 2005) and a growing body of work on fish (McNeill \& Fairweather, 1993; Eggleston et al., 1999; Bell et al., 2001; Laurel et al., 2003; Salita et al., 2003; Jackson et al., 2006a;
Jelbart et al., 2006). McNeill \& Fairweather (1993) found that a combination of two small seagrass beds consistently contained more fish species than one large seagrass bed of the same area. However, no such patterns were found for densities of individual fish (e.g. Eggleston et al., 1999 and reviewed by Bell et al., 2001).

In addition to bed size, the shape of a seagrass bed may also influence the interception of larvae or recruits because a long, narrow bed (with high perimeter to area ratio) has an increased likelihood of intercepting more animals than a rounder bed with a low perimeter to area ratio (Bologna \& Heck, 2000). Some researchers propose that the high perimeter to area ratio of numerous small patches may offer more advantages than one large habitat with a low perimeter to area ratio (Paine \& Levin, 1981; McNeill \& Fairweather, 1993). Therefore one may predict that a small seagrass bed with a high perimeter to area ratio (PAR) would contain a greater diversity of fish than a large bed with a low perimeter area ratio (Eggleston et al., 1999), although extreme fragmentation (with a high PAR) might be expected to exceed a fragmentation threshold and result in reduced diversity (Reed \& Hovel, 2006).

In a study of the macroinvertebrate assemblages in Zostera marina seagrass beds of Devon, UK, a relationship was found between the biomass of seagrass and the number of macroinvertebrate species (Attrill et al., 2000). It is thought that this indicates a species area relationship, but one brought about by a random sampling artefact in which increasing the area of seagrass sampled had a concurrent increase in the proportion of the macroinvertebrate population randomly sampled. We attempted to address this issue in the current study by including a test for a sampling artefact.

Previous studies have revealed that the location of a seagrass bed within an estuary can influence the abundance and diversity of fish found in that bed (Sogard, 1989; Jenkins et al., 1996; West \& King, 1996; Valle et al., 1999). The fish assemblages in the lower parts of an estuary are dominated by marine fish species and in the upper estuary are dominated by fish that can complete their life cycle within the estuary (Loneragan et al., 1986; Bell et al., 1988). Therefore any survey of fish within an estuary must also account for the potential confounding influence of the location of a seagrass bed within the estuary. Although the density and leaf height of a seagrass bed may be important for fish on a small scale, on the larger scale of the whole estuary, these influences could be masked by landscape features (Bell \& Pollard, 1989; Jelbart \& Ross, 2003).

The aim of this study was to determine the effects on small fish of seagrass bed size, shape, patchiness and position within the estuary during both day and night sampling. The predictions are that the size and shape of a seagrass bed will influence the diversity and abundance of fish in seagrass beds. This influence will either be independent or interact with the time of sampling (day or night), seagrass cover (patchy or continuous) and/or position of the bed within the estuary (near to and far from estuary mouth). We hypothesize that: (1) small seagrass beds will contain greater densities of fish species and individuals than larger beds; (2) beds with a higher PAR will contain greater densities of fish (species) than those with a lower PAR; (3) patchy beds will 
have different assemblages or densities of fish compared to continuous beds; and (4) there will be an influence of bed distance to estuary mouth on fish assemblages in seagrass.

\section{MATERIALS AND METHODS}

Study area and description

This study occurred during September to November 2000 (austral spring) in the Pittwater estuary north of Sydney, New South Wales, Australia (Figure 1). Fifteen monospecific beds of Zostera capricorni were selected based on their distribution throughout the estuary (Figure 1) and similar water depths (30-80 $\mathrm{cm}$ at mean low tide). Each bed was separated by over $200 \mathrm{~m}$ of bare sandy substratum and usually by much more.

\section{Size and patchiness of beds}

The seagrass beds were categorized into three size-groups based on natural breaks in the measurements and to give similar numbers of beds in each category: small (980 to 2300 $\mathrm{m}^{2}$ ), medium (3375 to $4090 \mathrm{~m}^{2}$ ) and large (5335 to $6630 \mathrm{~m}^{2}$ ). Water clarity is good in the Pittwater (to $10 \mathrm{~m}$ visibility) and this allowed us to clearly identify the outer perimeter of beds. The seagrass in Pittwater forms clearly defined beds as compared to some other estuaries in south-east Australia that have extensive meadows of interconnected patches. The edge of each bed was walked or boated around and every $2 \mathrm{~m}$ the longitude and latitude were recorded using a hand-held GPS unit. The perimeter and area of the seagrass beds were calculated using the GIS software ARC View ${ }^{\circledR}$. The perimeter to area ratio of the seagrass beds varied from 0.065 to 0.34 . The internal sand/seagrass interfaces of the patchy beds were not measured as edge or bed perimeter. A survey of the seagrass cover in each bed established that eight of the seagrass beds were patchy, while the other seven were continuous. The cover of seagrass within each bed was estimated by visual examination using 120 contiguous quadrats $(25 \times 25 \mathrm{~cm})$ arranged along 3 randomly placed $30 \mathrm{~m}$ transects. The continuous seagrass beds had only extremely small sand patches between 0 and $25 \mathrm{~cm}$ in total of the 30 $\mathrm{m}$ transect $($ mean $=2 \mathrm{~cm}, \mathrm{SE}=1.4)$. The patchy seagrass beds varied from 10 to $48 \%$ (average $27 \%$ ) in sand cover and contained individual sand patches that were no more than 2 $\mathrm{m}$ in diameter. In this estuary the patchy seagrass could still be identified as discrete beds and so could be compared to continuous beds.

Both categories of seagrass, bed size (small, medium and large) and seagrass cover (patchy and continuous), were spatially interspersed throughout the estuary (Figure 1). The seagrass beds were further categorized by distance from the mouth of the estuary, which ranged from 1.8 to over $9 \mathrm{~km}$ (Figure 1). The influence of adjacent habitat (mangroves) was tested and found not to confound the results of this study and has been reported elsewhere as part of a larger study on adjacent habitats (Jelbart et al., 2007).

\section{Shoot density and blade length of seagrass}

The shoot density of each seagrass bed was estimated using eight random quadrats $(25 \times 25 \mathrm{~cm})$. The seagrass varied in average shoot densities (range 514-1166 shoots $\mathrm{m}^{-2}$,
Table 1. Fish caught in seagrass during the day and night.

\begin{tabular}{|c|c|c|c|}
\hline Family & Species & Day & Night \\
\hline Aplodactylidae & Cheilodactylus vestitus & 0 & 1 \\
\hline Atherinidae & Atherinomorus ogilbyi & 11 & 179 \\
\hline Batrachoididae & Batrachomoeus dubius & 0 & 3 \\
\hline Blenniidae & Petroscirtes lupus & 1 & 19 \\
\hline Callionymidae & Repomucenus calcaratus & 6 & 4 \\
\hline Chandidae & Ambassis jacksoniensis & 849 & 103 \\
\hline \multirow[t]{4}{*}{ Clinidae } & Cristiceps argyropleura & 0 & 1 \\
\hline & Cristiceps aurantiacus & 6 & 24 \\
\hline & Heteroclinus fasciatus & 6 & 21 \\
\hline & Heteroclinus sp. & 2 & 6 \\
\hline \multirow[t]{2}{*}{ Clupeidae } & Hyperlophus translucidus & 887 & 15 \\
\hline & Spratelloides robustus & 21 & 3 \\
\hline \multirow[t]{2}{*}{ Diodontidae } & Dicotylichthys punctulatus & 0 & 1 \\
\hline & Diodon nichthemerus & 0 & 2 \\
\hline Gerreidae & Gerres subfasciatus & 2 & 9 \\
\hline Girellidae & Girella tricuspidata* & 414 & 300 \\
\hline \multirow[t]{5}{*}{ Gobiidae } & Arenigobius frenatus & 266 & 1243 \\
\hline & Bathygobius kreffti & 79 & 471 \\
\hline & Cristatogobius gobioides & 0 & 1 \\
\hline & Favongobius tamarensis & 543 & 455 \\
\hline & Redigobius macroston & 33 & 61 \\
\hline Hemiramphidae & Hyporhamphus australis* & 0 & 1 \\
\hline \multirow[t]{3}{*}{ Labridae } & Achoerodus viridis & 28 & 3 \\
\hline & Halichoeres hortulanus & 1 & 0 \\
\hline & Stethojulis interrupta & 0 & 1 \\
\hline \multirow[t]{9}{*}{ Monacanthidae } & Acanthalutere spilomelanurus & 439 & 267 \\
\hline & Acanthalutere vittiger & 1 & 2 \\
\hline & Brachaluteres jacksonianus & 1 & 0 \\
\hline & Cantherhinus pardalis & 9 & 7 \\
\hline & Eubalichthys mosaicus & 10 & 7 \\
\hline & Meuschenia trachylepis & 6 & 4 \\
\hline & Meuschenia venusta & 51 & 72 \\
\hline & Monacanthus chinensis & 5 & 2 \\
\hline & Scobinichthys granulatus & 53 & 83 \\
\hline \multirow[t]{3}{*}{ Mullidae } & Upeneichthys lineatus & 2 & 19 \\
\hline & Upeneus sp. & 4 & 14 \\
\hline & Upeneus tragula & 0 & 6 \\
\hline Odacidae & Neoodax balteatus & 5 & 5 \\
\hline Paralichthyidae & Pseudorhombus jenynsii & 3 & 2 \\
\hline Scorpaenidae & Centropogon australis & 39 & 199 \\
\hline \multirow[t]{3}{*}{ Sillaginidae } & Sillago maculata* & 0 & 10 \\
\hline & Sillaginodes punctatus* & 1 & 10 \\
\hline & Sillago flindersi* & 1 & 1 \\
\hline & Rhabdosargus sarba* & 276 & 447 \\
\hline \multirow[t]{6}{*}{ Syngnathidae } & Festucalex cinctus & 0 & 1 \\
\hline & Filicampus tigris & 7 & 10 \\
\hline & Hippocampus whitei & 4 & 4 \\
\hline & Stigmatopora argus & 4 & 3 \\
\hline & Stigmatopora nigra & 137 & 104 \\
\hline & Urocampus carinirostris & 176 & 178 \\
\hline Tetraodontidae & Tetractenos hamiltoni & 2 & 1 \\
\hline Terapontidae & Pelates sexlineatus & 132 & 230 \\
\hline
\end{tabular}

*, species of recreational and/or commercial importance.

mean=532, $\mathrm{SE}=48$ ) and average blade length (range 7.5-22.5 $\mathrm{cm}$, mean=13.2, $\mathrm{SE}=1.1$ ). Regression analysis demonstrated that these variables were not correlated with the densities of fish species or fish individuals (all $P>0.05$ ) and we therefore do not report those relationships in detail here. The shoot 

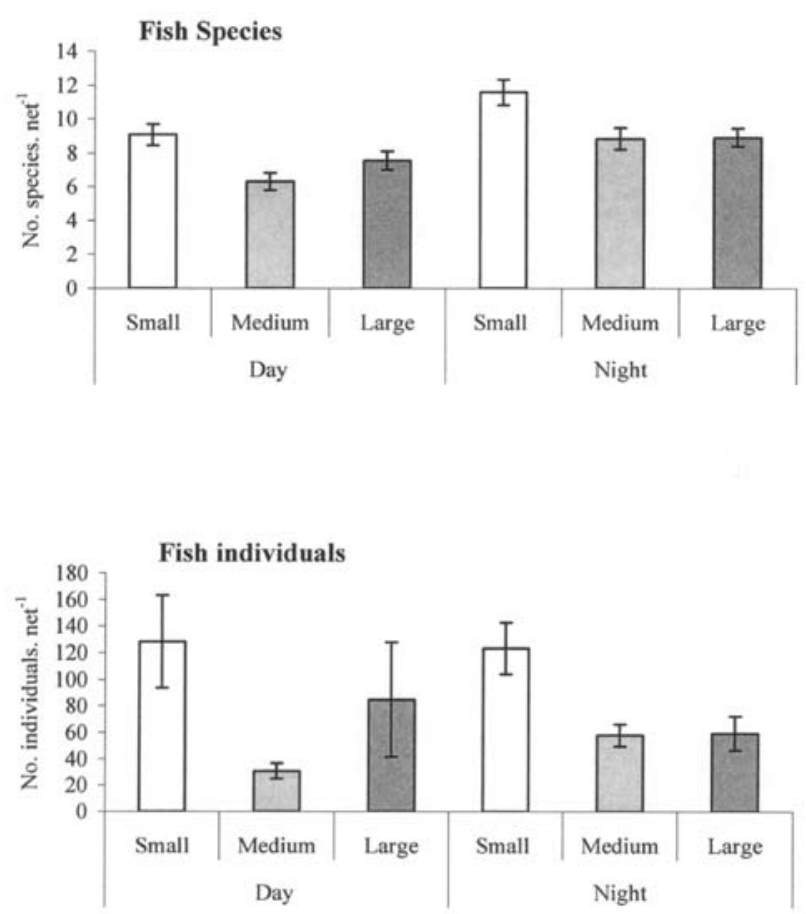

Figure 2. The number of fish species and fish individuals per net in the small, medium and large beds during the day and night.

density and leaf length were also not correlated with the distance of the bed from the estuary mouth so were not used as covariates in subsequent analyses.

\section{Sampling of fish}

Fish were collected with an $8 \times 2 \mathrm{~m}$ seine net $(1 \mathrm{~mm}$ mesh), on the low to mid tide (40-80 cm), sampling an area approximating $68 \mathrm{~m}^{2}$ (mean=68.2, $\mathrm{SE}=1.2$ ). Previous research has shown that this tidal state and water depth is the most effective for the seine net in terms of the number of species caught (Jelbart, 2004). This small seine net captures small and juvenile fish more effectively than larger pelagic fish (Connolly, 1994b; Guest et al., 2003), and it is these smaller fish that were the focus of the project. A total of four drags of the net were taken in each bed during the day and night (8 in total). We randomized the sampling so that individual nets within a bed were pulled on different days, ensuring temporal interspersion of sampling.

\section{Detection of sampling artefact}

Terrestrial studies that compare the biodiversity of large and small habitats often sample the whole area (Mazerolle \& Villard, 1999), but this creates a sampling artefact whereby more area is sampled in the large habitat than the small. To avoid this passive (random) sampling error the same area in large and small beds was sampled. Sampling in this way can, however, present a second sampling artefact where a larger proportion of a small bed is sampled. In this situation, the number of species may accumulate at a faster rate per sampling effort in small compared to large beds. To test for this 'accumulation' artefact, the accumulated number of fish species was plotted for each consecutive drag of the net for each bed. If a small bed accumulated fish species at a greater rate than a large bed the slope of the regression line would be steeper. For every bed, the rate of species accumulation was calculated (i.e. the slope of the regression line) and then plotted against the size of the bed. A regression analysis was then used to detect a relationship between the size of a bed and the rate of species accumulated during sampling. This was tested using day and night data separately. There was no relationship between the rate of species accumulated and the size of the seagrass bed (day, $\mathrm{R}^{2}=0.16, P=\mathrm{ns}$; night, $\left.\mathrm{R}^{2}=0.01, P=\mathrm{ns}\right)$. There was thus no evidence of a sampling artefact when sampling beds of different sizes.

\section{Univariate data analysis}

Analysis of variance (ANOVA) tests were performed on the density (number net ${ }^{-1}$ ) of fish species, fish individuals and the most numerous single species collected from the seagrass beds. The ANOVA contained four factors: time of sampling (fixed), heterogeneity of cover (fixed and orthogonal), size of bed (fixed and orthogonal) and beds (random and nested). Another three factor ANOVA was performed on the total number of fish and fish species richness per bed (factors: time of sampling, size of bed and seagrass bed). A Cochran's test was used to detect heterogeneity of variances and the data were transformed $\left(\ln \left(\mathrm{x}^{+}+1\right)\right)$ if the Cochran's test was significant. All analyses reported in this paper had a nonsignificant Cochran's test after transformation. Student Newman Kuels (SNK) tests were used to detect post-hoc differences among means.

A linear regression was used to test for a relationship between the perimeter area ratio of a seagrass bed and the density of fish species and individuals (number net ${ }^{-1}$ ). Similarly, these variables (and the densities of the more numerous single species) were tested for a correlation with the distance of the bed from the estuary mouth.

\section{Multivariate data analysis}

A Bray-Curtis similarity analysis between samples was performed after a square root transformation and used to create a non-metric multi-dimensional scaling (MDS) plot. A two-way crossed analysis of similarity (ANOSIM) was used to compare fish assemblages between day and night and beds of different sizes ( The MDS plots produced to illustrate these comparisons display pooled data for clarity. The day and night data were analysed separately for another two-way crossed ANOSIM to test for differences in assemblages between patchy $(\mathrm{N}=8)$ and continuous $(\mathrm{N}=7)$ beds and between beds close $(\mathrm{N}=8)$ and $\operatorname{far}(\mathrm{N}=7)$ from the estuary mouth. A SIMPER (similarity percentages) calculation revealed which species were driving any differences detected.

\section{RESULTS \\ Comparison of day and night sampling}

There were 52 species of fish and 9350 individuals caught, including six species of recreational and/or commercial importance (Table 1). The densities of fish species were significantly greater at night than during the day (Figure 2; Table 2; SNK night $>$ day), although there was no 
Day (0) vs. Night ( $\mathbf{\Delta}$ )

Global $\mathrm{R}=0.19, P=0.005$

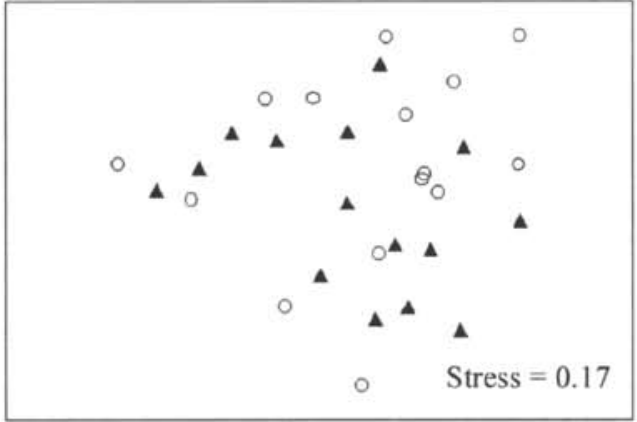

Day samples: Cover comparison

Patchy (囚) vs. Continuous (

Global $\mathrm{R}=0.25, P=0.001$

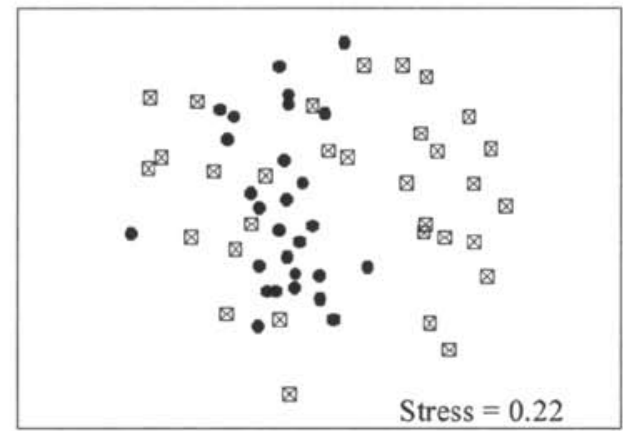

Day samples: Estuary comparison

Close $(\diamond)$ vs. Far $(\diamond)$ from mouth

Global $\mathrm{R}=0.40, P=0.001$

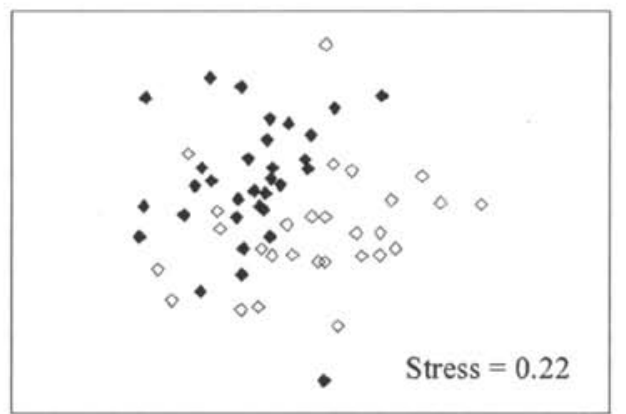

Small (+) Medium ( $\Delta)$ \& Large (匹)

Global $\mathrm{R}=0.14, P=0.002$

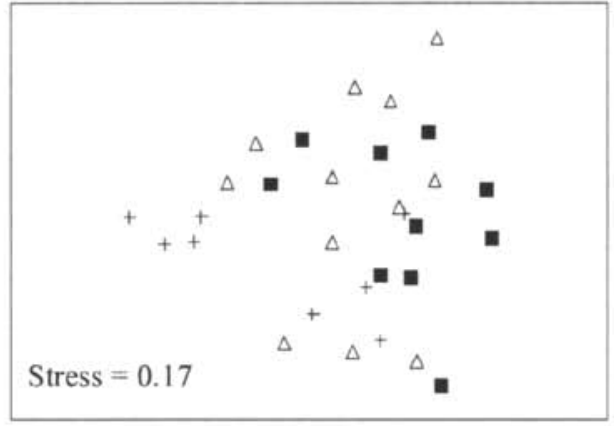

Night samples: Cover comparison

Patchy ( $₫)$ vs. Continuous

Global $\mathrm{R}=0.19, P=0.003$

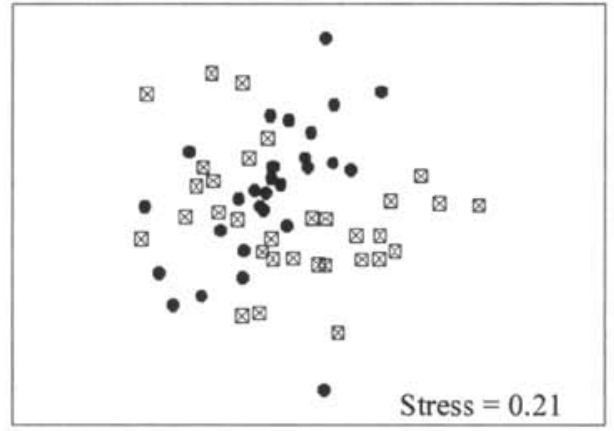

Night samples: Estuary comparison

Close $(\diamond)$ vs. Far $(\diamond)$ from mouth

Global $\mathrm{R}=0.51, P=0.001$

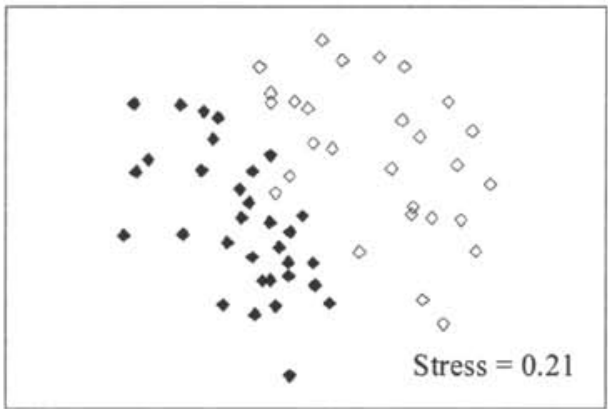

Figure 3. Two-dimensional configurations for multi-dimensional scaling (MDS) ordinations comparing fish assemblages during the night and day; in small, medium and large beds; in patchy and continuous beds; in beds close and far from the estuary mouth. ANOSIM results are shown for each comparison, including the Global $\mathrm{R}$ and $P$ value.

corresponding difference in the densities of fish individuals (Figure 2; Table 2). The fish assemblages during the day were different from those in the night (Figure 3), although the low $\mathrm{R}$ value suggests the dissimilarity was not great. The species that were more abundant during the night than the day were Arenigobius frenatus, Atherinomorus ogilbyi and Bathygobius kreffti. Only one species, Acanthalutere spilomelanurus, was more abundant in the day than in the night (Table 3).

\section{Patchiness of seagrass cover}

Patchy and continuous beds had similar densities of fish individuals and species (Table 2), but differed in their assemblage composition (Figure 3). The low global R value suggests a high degree of dispersion in the groupings and caution should be used in interpreting these results, although the $P$ value indicates a significant difference. The $\mathrm{R}$ value was greater for the day sampling than the night 
Table 2. ANOVA results comparing the density of fish species and fish individuals collected at different times (day and night), from beds of different cover (patchy or continuous) and size (small, medium or large).

\begin{tabular}{|c|c|c|c|c|c|}
\hline Source of variation & $\mathrm{df}$ & Mean squares & $\mathrm{F}$ & Mean squares & $\mathrm{F}$ \\
\hline & \multicolumn{3}{|c|}{ No. species net ${ }^{-1}$} & \multicolumn{2}{|c|}{ No. individuals net ${ }^{-1} \ln \left(x^{+1}\right)$} \\
\hline Time & 1 & 90.1 & $8.1^{*}$ & 3.4 & 2.7 \\
\hline Cover & 1 & 3.8 & 0.4 & 1.5 & 1.0 \\
\hline Size & 2 & 95.7 & $9.5^{*}$ & 12.8 & $8.2^{*}$ \\
\hline Beds (cover×size) & 6 & 10.1 & 1.4 & 1.6 & $2.8^{*}$ \\
\hline Timexcover & 1 & 0.5 & 0.1 & 0.1 & 0.1 \\
\hline Timexsize & 2 & 1.9 & 0.2 & 1.2 & 1.0 \\
\hline Timexbed (cover×size) & 6 & 11.2 & 1.6 & 1.2 & 2.3 \\
\hline Cover $\times$ size & 2 & 1.3 & 0.1 & 4.0 & 2.6 \\
\hline Time $\times$ cover $\times$ size & 2 & 6.9 & 0.6 & 2.7 & 2.2 \\
\hline Residual & 72 & 7.1 & & 0.6 & \\
\hline
\end{tabular}

$*, P<0.05$

Table 3. Summary of ANOVA results comparing individual fish species at different times (day and night), in beds of different cover (patchy and continuous) and size (small, medium and large). F values are shown.

\begin{tabular}{|c|c|c|c|c|c|c|c|c|c|}
\hline Species name & $\begin{array}{l}\text { Time } \\
\mathrm{df}=1\end{array}$ & $\begin{array}{c}\text { Cover } \\
\mathrm{df}=1\end{array}$ & $\begin{array}{l}\text { Size } \\
d f=2\end{array}$ & $\begin{array}{c}\text { Beds } \\
\left(\begin{array}{c}\text { (cover } \times \text { size }) \\
\mathrm{df}=6\end{array}\right.\end{array}$ & $\begin{array}{c}\text { Timexcover } \\
\mathrm{df}=1\end{array}$ & $\begin{array}{c}\text { Time } \times \text { size } \\
\mathrm{df}=2\end{array}$ & $\begin{array}{c}\text { Time } \times \text { beds } \\
\begin{array}{c}\text { (cover } \times \text { size }) \\
\mathrm{df}=6\end{array}\end{array}$ & $\begin{array}{c}\text { Cover } \times \text { size } \\
\mathrm{df}=2\end{array}$ & $\begin{array}{c}\text { Time } \times \text { cover } \times \text { size } \\
\mathrm{df}=2\end{array}$ \\
\hline Acanthalutere spilomelanurus & $6.2^{*}$ & 0.1 & 1.9 & $2.4^{*}$ & 0.3 & 1.6 & 0.9 & 1.2 & 0.0 \\
\hline Ambassis jacksoniensis & 0.2 & 1.2 & $148.8^{* * * *}$ & 0.1 & 0.8 & $16.2^{* *}$ & 0.0 & $132.2^{* * * *}$ & $27.1 * *$ \\
\hline Arenigobius frenatus & $8.0^{*}$ & 0.8 & 0.6 & $8.4^{* * * *}$ & 0.2 & 1.1 & 1.1 & 0.3 & 3.9 \\
\hline Atherinomorus ogilbyi & $7.8^{*}$ & 1.7 & 0.2 & $2.5^{*}$ & 1.7 & 0.1 & 1.4 & 0.6 & 0.4 \\
\hline Bathygobius kreffti & $32.5^{* *}$ & $9.7^{*}$ & 0.2 & $6.0^{* * * *}$ & 5.1 & 2.2 & 1.7 & 1.9 & 1.9 \\
\hline Girella tricuspidata & 2.8 & $26.6^{* *}$ & $17.6^{* *}$ & 1.3 & 2.8 & 0.8 & 0.3 & $17.3^{* *}$ & 1.3 \\
\hline Pelates sexlineatus & 2.7 & $10.0^{*}$ & 0.2 & $4.9 * *$ & 0.2 & 0.3 & 1.4 & 2.4 & 1.5 \\
\hline Rhabdosargus sarba & 2.0 & 2.1 & $5.1 *$ & $3.6^{* *}$ & 0.2 & 0.3 & 0.6 & 1.8 & 3.3 \\
\hline Stigmatopora nigra & 0.3 & $8.6^{*}$ & 1.1 & $3.9 * *$ & 2.2 & 0.8 & 1.0 & 1.1 & 0.5 \\
\hline
\end{tabular}

*, $P<0.05 ; * * P<0.01 ; * * * P<0.01$. Residual $\mathrm{df}=72 ;$ total $\mathrm{df}=95$.

sampling. The most discriminating species between patchy and continuous beds were Arenigobius frenatus, Acanthalutere spilomelanurus, Bathygobius kreffi and Urocampus carinirostris. These species were more abundant in the continuous beds than the patchy beds. In contrast, ANOVA revealed that the densities of Pelates sexlineatus were significantly greater in the patchy beds, while Stigmatopora nigra and B. kreffti were more numerous in continuous beds (Table 3).

\section{Size and shape of beds}

There were greater densities of fish species and individuals in the small compared to the medium and large beds (Figure 2; Table 2; SNK small $>$ medium=large), although fish individuals also varied among beds (Table 2, beds nested in cover $\times$ size interaction). The ANOSIM also detected a difference in assemblage composition between small, medium and large beds (Global $\mathrm{R}=0.14, P<0.01)$. A pairwise test found the differences in assemblages were between the small and large beds $(\mathrm{R}=0.26, P<0.05)$, although the low
$R$ value suggests that the dissimilarity is low. The medium and large beds were statistically similar $(\mathrm{R}=0.05, P=0.213)$ as were the small and medium beds $(\mathrm{R}=0.15, P=0.053)$.

The species richness during the day was similar in small, medium and large beds. At night, however, the small beds had significantly greater total species richness and total number of fish individuals (Figure 4). A few species of fish were found to be more numerous in the small than the medium and large beds, including Rhabdosargus sarba, Ambassis jacksoniensis and Girella tricuspidata (Table 3).

There was no relationship between the perimeter area ratio and the density of fish species in beds during the day or night. There was, however, a significant relationship between the perimeter area ratio and the density of fish individuals (Figure 5). There was an increase in the density of fish individuals with an increase in the perimeter area ratio of the bed. This relationship was more pronounced during the night than day. Some caution is required in interpreting this result because the last data point in the plot 


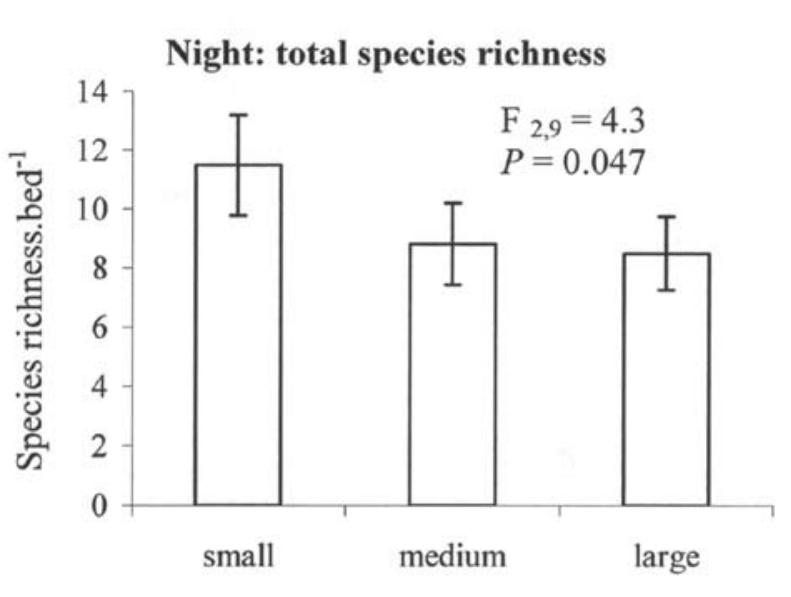

Size of seagrass beds

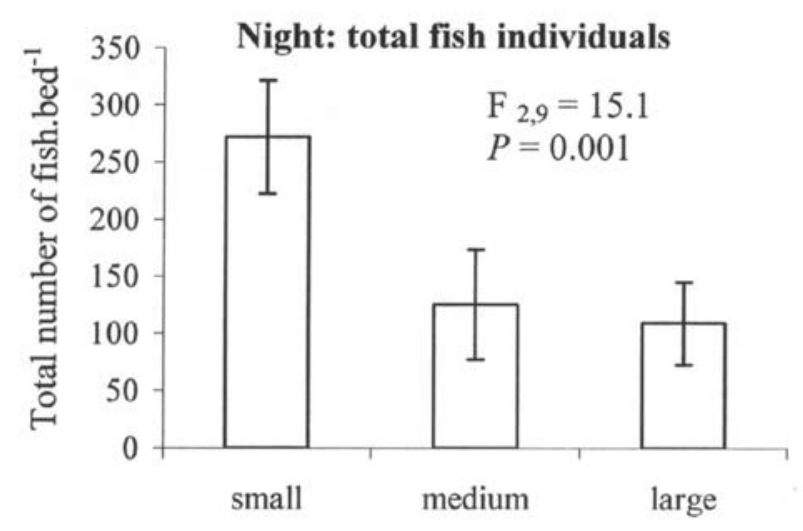

Size of seagrass beds

Figure 4. Plot of the species richness (total number of fish species per bed) and the total number of fish individuals in the small, medium and large beds from the night sampling. ANOVA results are shown on figures, including $\mathrm{F}$ value, degrees of freedom and $P$ value.

has considerable leverage on the regression line; when data were reanalysed without this point the slope was similar but the line was not significant $\left(\mathrm{R}^{2}=0.10, P=\mathrm{ns}\right)$.

\section{Location of beds in estuary}

There was no relationship between the distance of the bed from the estuary mouth and the mean density of fish species or individuals. There was, however, a relationship between the distance of the bed from the estuary mouth and fish assemblages within the bed (Figure 3). This was underpinned by significant relationships for the density of some individual species (Figure 6). The densities of Achoerodus viridis $\left(\mathrm{R}^{2}=0.39\right.$, $P=0.010)$, Bathygobius kreffti $\left(\mathrm{R}^{2}=0.53, P=0.001\right)$, Centropogon australis $\left(\mathrm{R}^{2}=0.51, P=0.002\right)$, Stigmatopora nigra $\left(\mathrm{R}^{2}=0.40\right.$, $P=0.009)$, Upenius sp. $\left(\mathrm{R}^{2}=0.37, P=0.012\right)$ and the Clinidae family $\left(\mathrm{R}^{2}=0.37, P=0.013\right)$, decreased as the distance of the seagrass beds to the estuary mouth increased (Figure 6). Only two species, Atherinomorus ogilbyi $\left(\mathrm{R}^{2}=0.23, P=0.058\right)$ and Pelates sexlineatus $\left(\mathrm{R}^{2}=0.53, P=0.001\right)$, were more abundant in beds far from the mouth (Figure 6).

\section{DISGUSSION \\ Comparison of day and night sampling}

The density of fish species in seagrass beds was greater during the night than the day. This pattern supports the work of other researchers (Bell \& Harmelin-Vivien, 1982; Gray et al., 1998; Letourneur et al., 2001) and confirms the need to incorporate sampling at night for fish in seagrass. One possible reason for this diel difference is that fish can more successfully avoid the net during the day than at night. Alternatively, at low tide during the day, fish may move into deeper water to escape avian predators. This avoidance would not be necessary during low tide at night.

\section{Seagrass shoot density and leaf length}

There was no relationship between the average seagrass shoot density or leaf length per bed and the total densities of all fish and fish species in this study. This is not to say that relationships between these small-scale features and fish are absent but in this study they were not detected because of the influences of the large-scale processes such as patch size and location of the bed in the estuary. Most studies that find a relationship with seagrass density/height do so with a certain group of fish, such as cryptic species (e.g. Jackson
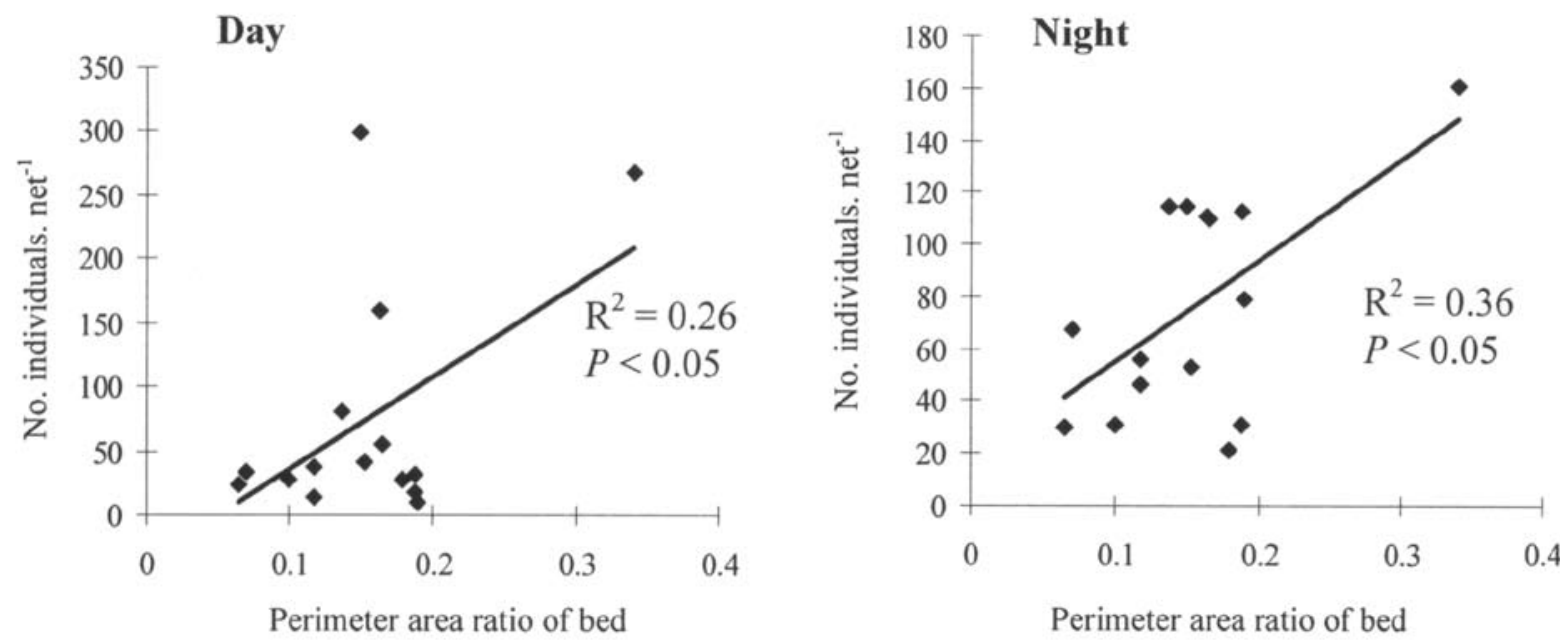

Figure 5. Plots of the mean number of individuals (all species) per net against the perimeter-area ratio of each bed during the day and night. 
A
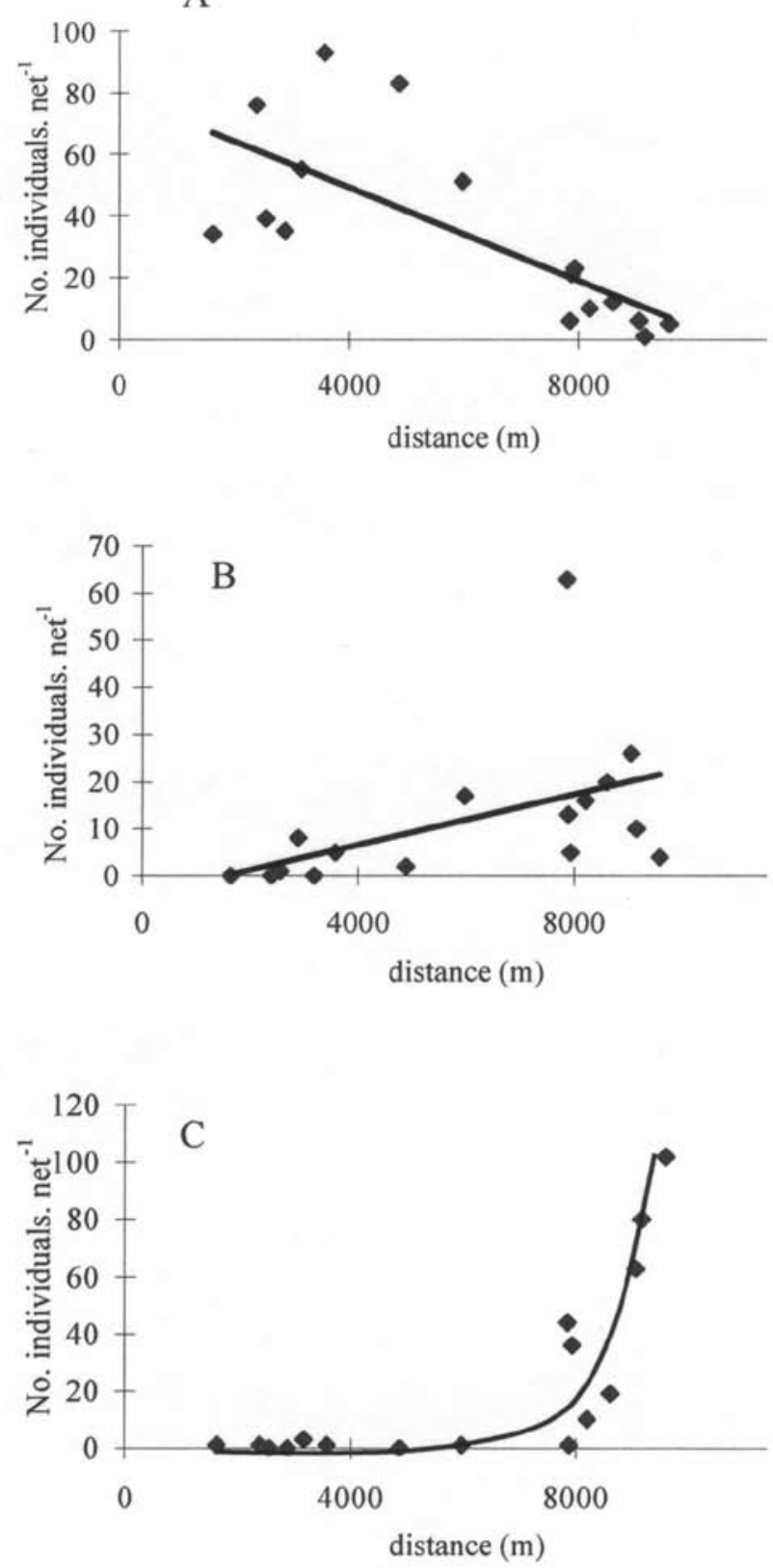

Figure 6. Relationships between the density of single species and the distance of the bed from the estuary mouth: (A) Bathygobius kreffit; (B) Atherinomorus ogilbyi; and (C) Pelates sexlineatus.

et al., 2006a), or individual fish species (e.g. Moranta et al., 2006). The lack of small-scale influences might be an attribute of the region of our study; other researchers in south-east Australia (e.g. Bell et al., 1987, 1988) have also failed to detect small-scale patterns when sampling across seagrass landscapes. For example, Bell et al. (1987) found that the settlement of juvenile fish was based not on physical complexity (i.e. leaf density) of seagrass but availability of larvae and settlement processes. There is one similar finding from outside south-east Australia in the eastern Mediterranean, where Moranta et al. (2006) found that the total fish composition was unrelated to seagrass structure (cover and density) in Posidonia oceanica beds.

\section{Patchiness of seagrass cover}

The patchiness of seagrass cover did not influence the density of fish species or individuals within a bed. Patchy beds did, however, have different assemblages of fish to continuous beds and this difference was more pronounced (greater $\mathrm{R}$ value) during the day than the night. Some cryptic species (Syngnathids; Stigmatopora nigra and Urocampus carinirostris) and some small permanent residents (mostly gobies; Arenigobius frenatus, Bathygobius kreffti and the leatherjacket Acanthalutere spilomelanurus) were more numerous in continuous beds. Only one fish species, Pelates sexlineatus, was more numerous in patchy than in continuous seagrass beds. Other studies have also found that individual species respond to the patchiness of seagrass cover (Salita et al., 2003; Jackson et al., 2006a). Similar to our findings, in the Philippines some syngnathids were more numerous in continuous beds (Salita et al., 2003), and in Jersey small permanent residents were also more abundant in continuous beds (Jackson et al., 2006a).

Another study in Jersey (Jackson et al., 2006b) found that the total density of fish was inversely related to the heterogeneity of the trawl area and the most abundant species were cryptic and small permanent residents. In our study, the apparent lack of a response for the total fish abundance to the patchiness of a seagrass bed is similar to the findings of Salita et al. (2003), who suggested that patchy beds contain similar numbers of fish as continuous beds. We suspect that in our study, the level of patchiness (10-48\% sand composition per patchy bed) was not sufficient to cause a decline in total fish abundances. This is supported by a study of eelgrass fragmentation (Reed \& Hovel, 2006), where there was no correlation between seagrass loss and epifauna abundance until a fragmentation threshold was reached (90\% removal of eelgrass), which then caused a significant change in epifaunal assemblages. We suggest that even small fish are more reliant on the macrohabitat (i.e. the whole seagrass bed) than the microhabitat (i.e. cover of seagrass within the bed).

\section{Size and shape of beds}

Smaller beds had greater densities of fish species and individuals than medium and large beds. The smaller beds also had greater species richness than the medium or large beds, although this was statistically significant only for night catches. These results did not simply arise as a sampling artefact. McNeill \& Fairweather (1993) made a similar finding, of greater species richness in two beds compared to one bed of the same total size. They hypothesized that this was because there is a greater likelihood of sampling an edge in a small bed. The edges of seagrass patches have been found to contain greater abundances of some fauna than the interiors (e.g. Holt et al., 1983; Bologna \& Heck, 2000; Tanner, 2004), so researchers have considered the likelihood of sampling an edge to be the reason why more fauna is collected from small seagrass beds (McNeill \& Fairweather, 1993; Bologna \& Heck, 2000; Bell et al., 2001). However, other studies have found fauna to be less dense at the edge than inner regions of seagrass beds (e.g. SanchezJerez et al., 1999; Hovel et al., 2002; Hovel \& Lipcius, 2002). This conflicting evidence could potentially arise from an interaction between edge effects and bed size. For example, 
a study in the Pittwater has detected edge effects within large seagrass beds but not in small beds (Jelbart et al., 2006). The edge ( $4 \mathrm{~m}$ outer perimeter) and inner regions of both small and large beds were sampled for fish and the effect of edge interacted with bed size. The edges of the large beds had significantly lower species densities than the inner regions of the small and large beds and the edges of the small beds.

The most commonly cited mechanism underlying different fish abundances in small and large seagrass beds is predation (e.g. Irlandi et al., 1999; Hovel \& Lipcius, 2001; Laurel et al., 2003). It has been proposed that smaller seagrass beds may be too small to support large abundances of top predators (Eggleston et al., 1998, 1999; Hovel \& Lipcius, 2001). Hovel \& Lipcius (2001) found that the survival of juvenile blue crabs increased as the size of seagrass beds decreased. This was because smaller beds of seagrass could not support the predatory adult blue crab. Predation rates have also been shown to be higher on seagrass patch edges for some fauna (Bologna \& Heck 1999). This is the reason proposed for the lower densities of fish species in the edges of the large seagrass beds than the small seagrass beds (Jelbart et al., 2006).

An alternative explanation for the greater density of fish species in small beds is the limited area available for the settlement of fish larvae. If a small and large bed receives a similar number of larvae (as suggested by Bell et al., 1987), then a greater density of larvae may accumulate in small compared to large beds. It is known that the larvae of some commercial and recreational fish can remain in seagrass beds for several months after settling from the plankton, before moving to other habitats (Middleton et al., 1984; Worthington et al., 1992). During this period of low dispersal, larvae may survive and concentrate in greater densities in the small compared to large beds.

\section{Location of beds in estuary}

The fish assemblages in seagrass beds close to the estuary mouth were significantly different from those in beds located far from the mouth of the estuary. There were, however, no detected differences in the density of fish individuals and fish species regardless of the distance to the mouth of the estuary. Previous work in the same estuary found that the abundances of juveniles of many fish species were affected by the location of the bed within the estuary (Bell et al., 1988). They reasoned that this was because of the combined effects of spawning location and the dispersal of eggs and larvae. The Pittwater estuary is dominated by marine waters for much of the year, and this lack of strong salinity gradient implies that differences in fish assemblages with distance into the estuary is not the result of the salinity gradient (Bell et al., 1988). Instead, we suggest that the proximity to oceanic currents that transport larvae into an estuary, a factor known to affect fish assemblages in other places in south-east Australia (Connolly, 1994a; West \& King, 1996; Jenkins et al., 1997), is part of the explanation.

\section{Combination and interaction of landscape influences on fish}

The influences of landscape features on fish in seagrass beds is dependant on the scale of the feature that is being measured and, from our results, appears to interact with other features at different scales. This supports the call for encompassing multiple spatial scales when attempting to understand ecological processes within seagrass landscapes (Moranta et al., 2006). For example, the location of a bed in an estuary may be the strongest influence on the composition of fish assemblages (the highest $\mathrm{R}$ value from multivariate analyses). Studies addressing fish distributions and abundances in estuaries of south-east Australia should acknowledge this factor when examining assemblages. Other variables are important determinants of total abundances of fish and fish species. The size of a bed is the most important factor for determining fish species densities and fish abundances, i.e. smaller seagrass beds contain greater densities than larger beds. The mechanism for this pattern was not investigated, but other studies have attributed this to edge effects (Bell et al., 2001; Jelbart et al., 2006). The size of the bed has a weak influence on the composition of the fish assemblage. Similarly, seagrass cover (patchy or continuous) had a significant influence on fish assemblages but less so than bed position in the estuary.

\section{Implications for management of estuaries}

The size of a seagrass bed was the most influential landscape feature on the densities of small fish. For this reason, small seagrass beds should not be overlooked when designating protected areas in estuaries. Larger beds with lower densities might nevertheless supply recruits to small beds. At this stage, we therefore recommend that a range of different sized beds, close to and far from the mouth, should be included to protect the diversity of fish in an estuary.

This study was made possible by an Ethel Mary Read research grant from the Royal Zoological Society (to J.J.), and the support of the School of Natural Sciences in the College of Science, Technology and Environment at the University of Western Sydney. Thanks also to the team of field assistants including C. Herlihy, K. Stephenson, C. Baker, R. Janus, A. Hayes and S. Claus. This research was conducted within institutional, national and international guidelines for the use of animals in research.

\section{REFERENCES}

Attrill, M.J., Strong, J.A. \& Rowden, A.A., 2000. Are macroinvertebrate communities influenced by seagrass structural complexity? Ecography, 23, 114-121.

Bell, J.D. \& Harmelin-Vivien, M.L., 1982. Fish fauna of French Mediterranean Posidonia oceanica seagrass meadows. 1. Community structure. Tethys, 10, 337-347.

Bell, J.D. \& Pollard, D.A., 1989. Ecology of fish assemblages and fisheries associated with seagrasses. In Biology of the seagrasses: a treatise on the biology of seagrasses with special reference to the Australian region (ed. A.W.D. Larkum et al.), pp. 565-609. Amsterdam: Elsevier.

Bell, J.D., Steffe, A.S., \& Westoby, M., 1988. Location of seagrass beds in estuaries: affects on associated fish and decapods. Fournal of Experimental Marine Biology and Ecology, 122, 127-146.

Bell, J.D. \& Westoby, M., 1986. Variation in seagrass height and density over a wide spatial scale: effects on common fish and decapods. Fournal of Experimental Marine Biology and Ecology, 104, 275-295.

Bell, J.D., Westoby, M. \& Steffe, A.S., 1987. Fish larvae settling in seagrass beds of different leaf density? Fournal of Experimental Marine Biology and Ecology, 111, 134-144. 
Bell, S.S., Brooks, R.A., Robbins, B.D., Fonseca M.S. \& Hall. M.O., 2001. Faunal response to fragmentation in seagrass habitats: implications for seagrass conservation. Biological Conservation, 100, 115-123.

Bell, S.S., Hall, M.O., Soffian, S. \& Madley K., 2002. Assessing the impact of boat propeller scars on fish and shrimp utilizing seagrass beds. Ecological Applications, 12, 206-217.

Bologna, P.A.X. \& Heck., K.L., 1999. Differential predation and growth rates of bay scallops within a seagrass habitat. Fournal of Experimental Marine Biology and Ecology, 239, 299-314.

Bologna, P.A.X. \& Heck, K.L., 2000. Impacts of seagrass habitat architecture on bivalve settlement. Estuaries, 23, 449-457.

Boström, C., Jackson, E.L. \& Simenstad, C.A., 2006. Seagrass landscapes and their effects on associated fauna: a review. Estuarine, Coastal and Shelf Science, 68, 383-403.

Connolly, R.M., 1994a. A comparison of fish assemblages from seagrass and unvegetated areas of a southern Australian estuary. Australian Fournal of Marine and Freshwater Research, 45, 1033-1044.

Connolly, R.M., 1994b. Comparison of fish catches from a buoyant pop net and a beach seine net in a shallow seagrass habitat. Marine Ecology Progress Series, 109, 305-309.

Connolly, R.M. \& Hindell, J.S., 2006. Review of nekton patterns and ecological processes in seagrass landscapes. Estuarine, Coastal and Shelf Science, $\mathbf{6 8}, 433-444$.

Eggleston, D.B., Elis W.E., Etherington L.L., Dahlgren C.P. \& Posey, M.H., 1999. Organism responses to habitat fragmentation and diversity: habitat colonization by estuarine macrofauna. Fournal of Experimental Marine Biology and Ecology, 236, 107-132.

Eggleston, D.B., Etherington L.L. \& Elis W.E., 1998. Organism response to habitat patchiness: species and habitat-dependent recruitment of decapod crustaceans. Fournal of Experimental Marine Biology and Ecology, 223, 111-132.

Ferrell, D.J. \& Bell, J.D., 1991. Differences among assemblages of fish associated with Zostera capricorni and bare sand over a large spatial scale. Marine Ecology Progress Series, 72, 15-24.

Gray, C.A., Chick, R.C. \& McElligott, D.J., 1998. Diel changes in assemblages of fishes associated with shallow seagrass and bare sand. Estuarine, Coastal and Shelf Science, 46, 849-859.

Guest, M., Connolly, R.M. \& Loneragan, N.R., 2003. Seine nets and beam trawls compared in the day and night for sampling fish and crustaceans in shallow seagrass habitat. Fisheries Research, 64, 185-196.

Healey, D. \& Hovel, K.A., 2004. Seagrass bed patchiness: effects on epifaunal communities in San Diego Bay, USA. Journal of Experimental Marine Biology and Ecology, 313, 155-174.

Heck, K.L. \& Orth, R.J., 1980. Seagrass habitats: the role of habitat complexity, competition and predation in structuring associated fish and motile macroinvertebrate assemblages. In Estuarine perspectives (ed. V.S. Kennedy), pp. 449-461. New York: Academic Press.

Holt, S.A., Kitting, C.L. \& Arnold, C.R., 1983. Distribution of young red drums among different seagrass meadows. Transactions of the American Fisheries Society, 112, 267-271.

Hovel, K.A. \& Fonseca, M.S., 2005. Influence of seagrass landscape structure on the juvenile blue crab habitat-survival function. Marine Ecology Progress Series, 300, 179-191.

Hovel, K.A., Fonseca, M.S., Myer, D., Kenworthy, W. \& Whitfield, P., 2002. Effects of seagrass landscape structure, structural complexity and hydrodynamic regime on macrofaunal densities in North Carolina seagrass beds. Marine Ecology Progress Series, 243, 11-24.

Hovel, K.A. \& Lipcius, R.N., 2001. Habitat fragmentation in a seagrass landscape: patch size and complexity control blue crab survival. Ecology, 82, 1814-182.

Hovel, K.A. \& Lipcius, R.N., 2002. Effects of seagrass habitat fragmentation on juvenile blue crab survival and abundance. Fournal of Experimental Marine Biology and Ecology, 271, 75-98.
Irlandi, E.A., 1994. Large- and small-scale effects of habitat structure on rates of predation: how percent coverage of seagrass affects rates of predation and siphon nipping on an infaunal bivalve. Oecologia, 98, 176-183.

Irlandi, E.A., Orlando, B.A. \& Ambrose, W.G., 1999. Influence of seagrass habitat patch size on growth and survival of juvenile bay scallops, Argopecten irradians concentricus (Say). Fournal of Experimental Marine Biology and Ecology, 235, 21-43.

Jackson, E.L., Rowden, A.A., Attrill, M.J., Bossy, S.F. \& Jones, M.B., 2001. The importance of seagrass beds as a habitat for fishery species. Oceanography and Marine Biology, 39, 269-303.

Jackson, E.L., Rowden, A.A., Attrill, M.J., Bossy, S.F. \& Jones, M.B., 2002. Comparison of fish and mobile macroinvertebrates associated with seagrass and adjacent sand at St. Catherine Bay, Jersey (English Channel): emphasis on commercial species. Bulletin of Marine Science, 71, 1333-1341.

Jackson, E.L., Attrill, M.J., Rowden, A.A. \& Jones, M.B., 2006a. Seagrass complexity hierarchies: influence on fish groups around the coast of Jersey (English Channel). Fournal of Experimental Marine Biology and Ecology, 330, 38-54.

Jackson, E.L., Attrill, M.J. \& Jones, M.B., 2006b. Habitat characteristics and spatial arrangement affecting the diversity of fish and decapod assemblages of seagrass (Zostera marina) beds around the coast of Jersey (English Channel). Estuarine, Coastal and Shelf Science, $\mathbf{6 8}, 421-432$.

Jelbart, J.E., 2004. The influence of seascape spatial features on the fish and macroinvertebrates in seagrass beds. $\mathrm{PhD}$ thesis, University of Western Sydney, NSW, Australia.

Jelbart, J.E. \& Ross, P.M., 2003. What features matter when designing protected areas for fish in beds of seagrass: a review. In World Congress on Aquatic Protected Areas Proceedings, Cairns, Australia August 2002 (ed. J.P. Beumer et al.). St Lucia, Queensland, Australia: University of Queensland Press.

Jelbart, J.E., Ross, P.M. \& Connolly, R.M., 2007. Fish assemblages in seagrass beds are influenced by the proximity of mangrove forests. Marine Biology, 150, 993-1002.

Jelbart, J.E., Ross, P.M. \& Connolly, R.M., 2006. Edge effects and patch size in seagrass landscapes: An experimental test using fish. Marine Ecology Progress Series, 319, 93-102.

Jenkins, G.P., Black, K.P., Wheatley, M.J. \& Hatton, D.N., 1997. Temporal and spatial variability in recruitment of a temperate, seagrass associated fish is largely determined by physical processes in the pre- and post-settlement phases. Marine Ecology Progress Series, 148, 23-35.

Jenkins, G.P., Wheatley, M.J. \& Poore, A.G.B., 1996. Spatial variation in recruitment, growth and feeding of post settlement King George whiting, Sillaginodes punctata, associated with seagrass beds of Port Phillip Bay, Australia. Canadian Fournal of Fisheries and Aquatic Science, 53, 96-105.

Letourneur, Y., Darnaude, A., Salen-Picard, C. \& Harmelin-Vivien, M., 2001. Spatial and temporal variations of fish assemblages in a shallow Mediterranean soft-bottom area (Gulf of Fos, France). Oceanologica Acta, 24, 273-285.

Laurel, B.J., Gregory, R.S. \& Brown, J.A., 2003. Predator distribution and habitat patch area determine predation rates on Age-0 juvenile cod Gadus spp. Marine Ecology Progress Series, 251, 245-254.

Loneragan, N.R., Potter, I.C., Lenanton, R.C.J. \& Caputi, N., 1986. Spatial and seasonal differences in the fish fauna in the shallow of a large Australian estuary. Marine Biology, 92, 57586.

Mazerolle, M.J. \& Villard M.A., 1999. Patch characteristics and landscape context as predictors of species presence and abundance: a review. Ecoscience, 6, 117-124.

McNeill, S.E. \& Fairweather, P.G., 1993. Single large or several small marine reserves? An experimental approach with seagrass fauna. Fournal of Biogeography, 20, 429-440. 
Middleton, M.J., Bell, J.D., Burchmore, J.J., Pollard, D.A. \& Pease, B.C., 1984. Structural differences in the fish communities of Zostera capricorni and Posidonia australis seagrass meadows in Botany Bay, NSW. Aquatic Botany, 18, 89-109.

Moranta, J., Palmer, M., Morey G., Ruiz, A. \& Morales-Nin, B., 2006. Multi-scale spatial variability in fish assemblages associated with Posidonia oceanica meadows in the Western Mediterranean Sea. Estuarine, Coastal and Shelf Science, 68, 579-592.

Paine, R.T. \& Levin, S.A., 1981. Intertidal landscapes: disturbance and the dynamics of pattern. Ecological Monographs, 51, 145-178.

Reed, B.J. \& Hovel, K.A., 2006. Seagrass habitat disturbance: how loss and fragmentation of eelgrass Zostera marina influences epifaunal abundance and diversity. Marine Ecology Progress Series, 326, 133-143.

Salita,J.T., Ekau, W. \& Saint-Paul, U., 2003. Field evidence on the influence of seagrass landscapes on fish abundance in Bolinao, northern Phillipines. Marine Ecology Progress Series, 247, 183-195.

Sanchez-Jerez, P., Cebrian, C.B., \& Espla, A.A.R., 1999. Comparison of the epifauna spatial distribution in Posidonia oceanica, Cymodocea nodosa and unvegetated bottoms: importance of meadow edges. Acta Oecologica-International Fournal of Ecology, 20, 391-405.
Short, F.T. \& Wyllie-Echeverria, S., 1996. Natural and human induced disturbances of seagrasses. Environmental Conservation, 23, $17-27$.

Sogard, S.M., 1989. Colonization of artificial seagrass by fishes and decapod crustaceans: importance of proximity to natural eelgrass. Fournal of Experimental Marine Biology and Ecology, 133, $15-38$.

Tanner, J.E., 2004. Edge effects on fauna in fragmented seagrass meadows. Austral Ecology, 30, 210-218.

Valle, G.F., O'Brien,J.W. \& Wiese, K.B., 1999. Differential habitat use by California halibut, Paralichthys californicus, barred sand bass Paralabrax nebulifer, and other juvenile fishes in Alamitos Bay, California. Fisheries Bulletin, 97, 646-660.

West, R.J. \& King, R.J., 1996. Marine, brackish, and freshwater fish communities in the vegetated and bare shallows of an Australian coastal river. Estuaries, 19, 31-41.

Worthington, D.G., Ferrell, D.J., Mc Neill, S.E. \& Bell, J.D., 1992. Growth of four species of juvenile fish associated with seagrass Zostera capricorni in Botany Bay, NSW. Australian Fournal of Marine and Freshwater Research, 43, 1189-98.

Submitted 22 December 2005. Accepted 21 August 2007. 
